Journal of Case Reports 2018;8(1):4-6

\title{
Congenital Teratoid Cyst of the Tongue
}

\author{
Fakuade Babatunde Oludare ${ }^{1}$, Yusuf Mohammed Abdullahi ${ }^{2}$, Omitola Olufemi Gbenga ${ }^{3}$, Akpobi Ochuko Bright ${ }^{1}$
}

Departments of ${ }^{1}$ Dental/Maxillofacial Surgery and ${ }^{2}$ Histopathology, Federal Teaching Hospital Gombe; ${ }^{3}$ Department of Oral Pathology/Oral Biology, Dental Centre, University of Port Harcourt Teaching Hospital, P/Harcourt, Rivers State, Nigeria.

\author{
Corresponding Author: \\ Dr. Fakuade Babatunde Oludare \\ Email: ketretees31@gmail.com \\ This is an Open Access article distributed \\ under the terms of the Creative Commons \\ Attribution License (creativecommons.org/ \\ licenses/by/3.0). \\ Received \\ Accepted \\ Published
}

\begin{abstract}
Background: Teratoid cyst is a rare variant of dermoid cyst composed of tissues from the two or more germinal layers. They are seen in children and young adults, arising as a result of failure of closure of the embryonic branchial arches or migration of the germinal cells away from place of origin. Case Report: We describe a male infant with a teratoid cyst of the tongue. Conclusion: Treatment of choice in mature teratoid cyst is surgical excision.
\end{abstract}

Keywords: Branchial region, Dermoid cyst, Tongue, Tongue Diseases.

\section{Introduction}

Teratoid, dermoid and epidermoid cysts are uncommon developmental cyst, often called dysontogenic cyst. There are two theories suggesting the origination of these cysts, they can occur as a result of (i) entrapped ectodermal tissue of first and second branchial arches which fuse during the third and fourth week in utero, (ii) or as a variant of thyroglossal cyst [1]. Dermoid cysts are benign pathologies that occur anywhere in the body but more often in area of embryogenic fusion [1]. They are commonly seen in floor of mouth and the cervical region, but rarely seen in the tongue [2].

Teratoid cyst is the least common of the three variants of dermoid cysts and represents less than $0.01 \%$ of all oral cyst $[3,4]$. We present the clinical, histological findings and management of teratoid cyst in an infant.

\section{Case Report}

A 3 month old male child reported to the Dental/ Maxillofacial clinic of Federal Teaching Hospital
Gombe, with complaints from the mother, about a nodular mass below the tongue since birth. The swelling had been growing progressively in size raising the tongue and often disallowing the child from sucking. The intra-oral examination of the child's mouth revealed an ovoid mass on the ventral surface of the anterior two third of the tongue [Fig.1], tilting to the left ventral surface than the right ventral surface. Mucosa overlying the surface was intact with a hypereamic region on the right ventral surface; the swelling was basically firm but fluctuant in some area. Aspiration of the cystic mass yielded a viscous chocolate colored fluid, hence a provisional diagnosis of epidermoid cyst was made. Routine hematological investigation was carried out and hematocrit found to be $48 \%$, consequent upon which the patient was prepared for surgical excision under general aneasthesia.

A 2.0 vicryl stitch was passed through the tip of the tongue through and through to retract the tongue, and a midline ventral incision made, using a dissecting scissors the cystic mass was dissected from the tongue musculature [Fig.2]. The intra-operative blood loss was minimal and 


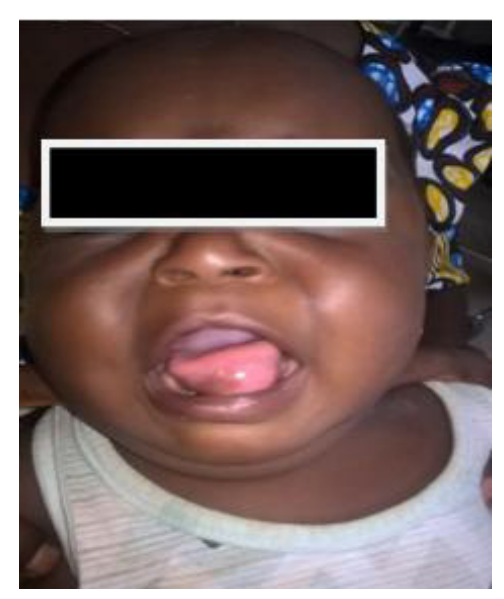

Fig.1: Cystic lesion on the tongue of the patient.

the wound closed with 3.0 vicryl suture using the continuous suture technique. Post-operative period was uneventful except for the slight tongue edema that resolved within a week of warm saline mouth bath with cotton wool. Intravenous antibiotics administered included ceftriazone $250 \mathrm{mg}$ twice daily, metronidazole $100 \mathrm{mg}$ thrice daily, for five days and paracetamol $100 \mathrm{mg}$ thrice daily for three days. Patient was discharged home after one week convalescent period.

Histopathologic examination revealed a cystic greyish white tissue, measuring $2.3 \times 1.7 \times 1.3 \mathrm{~cm}$, cut surface shows cystic cavity containing a greyish pasty material with a smooth cystic lining. Sections show a cyst lined by respiratory, intestinal and gastric type epithelial tissue with focal areas of stratified squamous epithelium, ulceration and granulation tissue. The overall features are in keeping with a benign cystic lesion and final diagnosis of mature teratoid cyst was made [Fig.4].

\section{Discussion}

Developmental cysts are the commonest cause of cystic masses affecting the head and neck region in children. Of these, thyroglossal cysts are the most common, accounting for $70 \%$ of the cases, followed by branchial cleft cyst. Most other cystic lesions are rarely encountered [5]. Epidermoid and

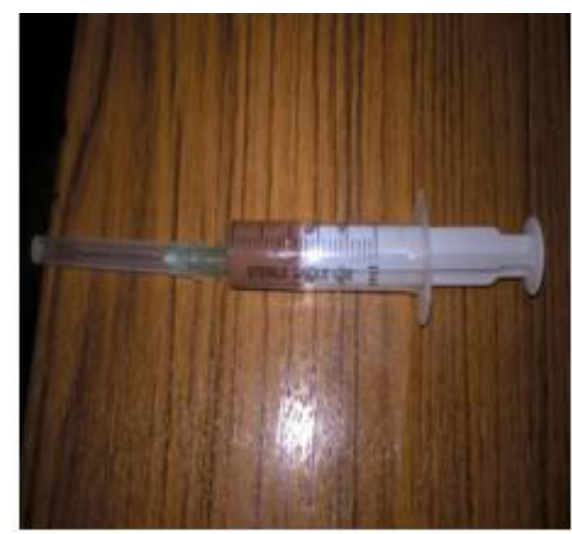

Fig.2: Dirty brown aspirate from the lesion.

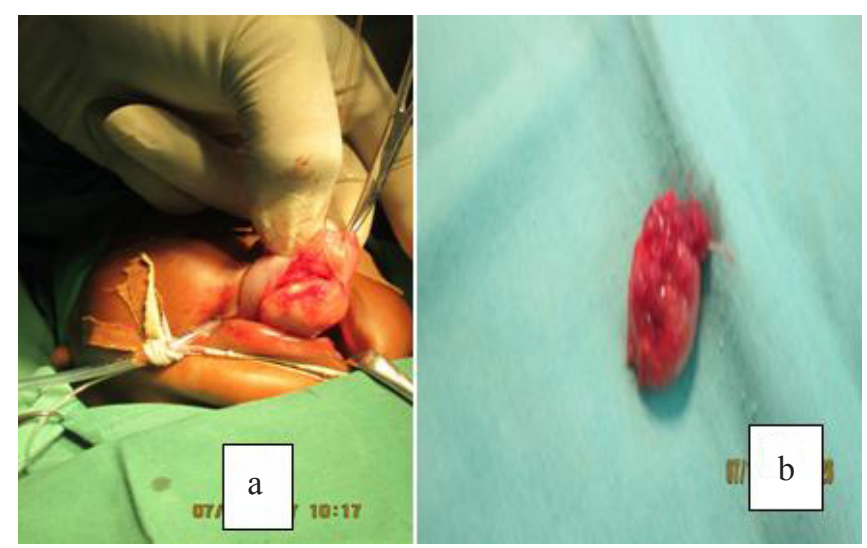

Fig.3: Lesion just before (a) and after surgical excision (b).

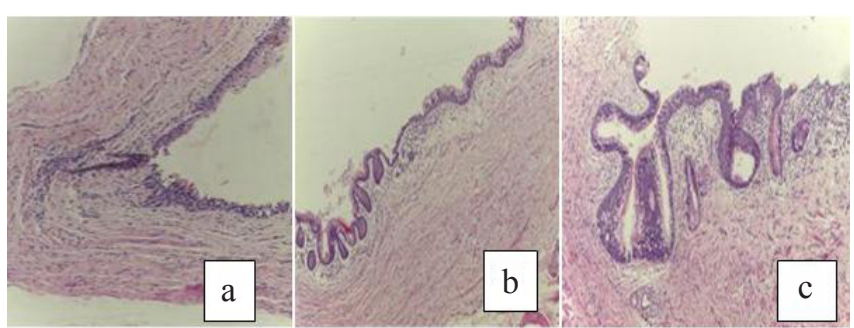

Fig.4: Lesion showing respiratory (a), transition between respiratory and gastric (b) and gastric (c) epithelia (H\&E $\times 10)$.

dermoid cysts occur throughout the body, with 7\% occurring in the head and neck region and 1.6\% within the oral cavity [4].

Majority of the case occur between the ages 15 and 35 years with a slight male predilection. For oral lesions, the floor of the mouth in the midline is the most common location. Lesions have also been 
reported in the buccal mucosa, tongue, lips, intraosseously in the mandible and maxilla [5]. The present case occurred in the tongue of an infant rarely seen in this age group [6]. It usually presents as a slow growing lesion but can grow to become substantially big causing respiratory distress if left untreated as reported by Akinbami et al. [7]. The differential diagnosis for dermoid cyst should include ranula (caused as a result of blockage of Wharton's duct), branchial cleft cyst, cellulitis of the floor of the mouth, heterotropic gastrointestinal cyst [8].

Treatment adopted in this case is surgical excision, this is the usual mode of treatment because recurrence of this lesion is very rare [6,7]. However, there had been reports of a number of complications such as infections, obliteration of the sinus ducts and malignant transformation especially of the teratoid variety $[2,9,10]$.

\section{Conclusion}

Teratoid cyst of the oral cavity is an unknown pathology, presenting as a slow growing tumor. Investigation in poor resource setting is limited to aspiration, incisional and excisional biopsy. If aspirate is clear-colored and slimy, the inkling is towards ranula, but in this rare case of a brownish aspirate a provisional diagnosis of a cyst was made. Treatment was by surgical excision.

Contributors: FBO: manuscript writing, literature review, patient management; YMA: manuscript editing, literature review, histopathology; OOG, AOB: critical inputs into the manuscript, and patient management. FBO will act as guarantor. All authors approved the final version of this manuscript.

Funding: None; Competing interests: None stated.

\section{References}

1. Koca H, Seckin T, Sipali A, Kaznac A. Epidermoid cyst in the floor of the mouth: report of a case. Quintessence Int. 2007;38:473-477.

2. Longo F, Maremonti P, Mangone G M, De Maria G., Midline (dermoid) cysts of the floor of the mouth: report of 16 cases and review of surgical techniques. Plast Reconstruc Surg. 2003;112:1560-1565.

3. Kandogan T, Koc M, Vardar E, Selek E, Sezgin O: Sublingual epidermoid cyst: a case report. J Med Case Report. 2007;1;8710.

4. De Ponte F S, Brunelli A, Marchatti E, Boltini D J. Sublingual epidermoid cyst. J Craniofac Surg. 2002;13:308-310.

5. Shear M, Speight P. Developmental cysts of head and neck. In: Shear M, editor. Cysts of the oral and maxillofacial Regions, $4^{\text {th }}$ ed. Denmark: Blackwell Munksgaard; 2008. pp. 181-191.

6. Palaskar SJ, Garde J, Bartake A, Narang B. Teratoid cyst of the oral cavity: A rare entity. J Oral Maxillofac Pathol. 2014;18:469-471.

7. Akinbami BO, Omitola OG, Obiechina AE. Epidermoid cyst of the tongue causing airway obstruction- A case report. J Maxillofac Oral Surg. 2011;10:349-353.

8. Ozan F, Polat HB, Ay S, Goze F. Epidermoid cyst of the buccl mucosa: a case report. J Contempo Dental Pract. 2007;3:90-96.

9. Pancholi A, Raninga S, Vohra PA, Vaidya V. Midline submental epidermoid cyst; a rare case. Internet $\mathrm{J}$ Otorhinolaryngol. 2006;2:74-77.

10. Devine JC, Jones DC. Carcinomatous transformation of sublingual dermoid cyst; a case report. Int J Maxillofac Surg. 2000;29:126-127. 